\title{
Treatment with L-thyroxine in congenital hypothyroidism
}

\begin{abstract}
Introduction: Thyroid hormone deficiency in embryonic development is associated with congenital hypothyroidism $(\mathrm{CH}) . \mathrm{CH}$ is the most common endocrine disease in newborns and the biggest preventable cause of mental retardation

Objective: Review recent medical evidence of the use of levothyroxine as a hormone replacement therapy for brain protection, improvement of growth and development and decrease cognitive deficits in $\mathrm{CH}$.

Materials and methods: The systematic review of PubMed/Medline databases, Redalyc, EBSCO, Virtual Health Library, Google Scholar. During period 2012-2017. Full text all world.

Results: Most authors recommend an initial dose of $10-15 \mu \mathrm{g} / \mathrm{kg} / \mathrm{day}$ and adjustments according to the patient's age and weight. It must be administered 2 hours before another food to avoid malabsorption. The monitoring of serum values every six to eight weeks helps to decide dose readjustment. The use of higher doses $(50 \mu \mathrm{g} / \mathrm{kg} /$ day $)$ and liquid solutions of levothyroxine in cases of severe $\mathrm{HC}$, show improvement in the growth and cognitive development.

Conclusion: The articles demonstrated medical evidence of improvement in somatometric and cognitive status in patients, causing an impact on symptom relief. The untreated $\mathrm{CH}$ causes alterations of the growth and mental retardation, its severity produces deep and irreversible neurological alterations, the reason why the opportune treatment after the birth is indispensable.
\end{abstract}

Keywords: congenital hypothyroidism, pediatric, pharmacological treatment, levothyroxine, using boolean operators AND and OR

Abbreviations: $\mathrm{CH}$, congenital hypothyroidism; $\mathrm{RCT}$, randomized clinical trials; $\mathrm{CCT}$, controlled clinical trials

\section{Introduction}

Thyroid hormone deficiency during embryonic development is associated with congenital hypothyroidism $(\mathrm{CH})$. $\mathrm{HC}$ is a syndrome that results from the biological hypoactivity of thyroid hormones during fetal life, either due to a deficit in their production, resistance to their action in the target tissues or alteration of their transport or metabolism; which mainly involves the central nervous system and the skeletal system. ${ }^{1}$ The untreated HC leads to alterations of growth and mental retardation, with clinical data of macroglossia, hypotonia, severe constipation and the umbilical hernia that, in its most severe forms, produces profound and irreversible neurological alterations. The brain damage is usually postnatal, due to the protection offered by the maternal thyroid hormone. This is why early treatment after birth achieves good results. ${ }^{2,3}$ The pharmacological treatment of primary congenital hypothyroidism is carried out through the use of substitution therapy. For this, Levothyroxine ${ }^{4-6}$ is commonly used. Therefore, the present work seeks to review the most recent medical evidence about the use of levothyroxine in hormone replacement therapy in the pediatric patient, as a factor of cerebral protection, as well as its benefits in improving growth and reducing deficiencies. Cognitive effects of these patients.

\section{Methods}

A systematic review of clinical trials, published between January
Volume 2 Issue 3 - 2018

\section{Maria Margarita Chávez Hernández, Ericka \\ Antonio Goméz, Marín Lavadores, William \\ Alberto, Sandoval Jurado Luis, Guerra \\ Rentería Sergio Geovanny, María Valeria Jiménez-Baez}

Mexican Social Security Institute, Clinical Cycles School of Medicine Quintana Roo University, Planning coordination and institutional link, México

Correspondence: Maria Valeria Jiménez Báez, Planning coordination and institutional link, University of Quintana Roo. Medicine School,Avenida Politécnico Nacional s/n Cancún, Quintana Roo, Mexico, Tel 052-9988742354,

EmailValeria.jimenezb@gmail.com

Received: June II, 2018 | Published: June 27, 2018
2012 and January 2017, that analyze patients with primary CH and are treated with hormone replacement therapies. Regarding the language of the publications, it was limited to Spanish and English, no geographic scope was specified. The studies that did not address primary $\mathrm{HC}$ or that did not use hormone replacement therapy to treat it, as well as those that did not conform to the type of study included..$^{7-10}$

\section{The electronic databases used were}

PubMed/Medline, Redalyc, EBSCO, Virtual Health Library, Google Scholar. The combination of keywords used was the same in the different databases and according to the characteristics and scope of coverage of these, the language of the keywords was adapted; in Spanish: Congenital hypothyroidism, Pediatric, Pharmacological treatment, as well as the term Levothyroxine, using the Boolean operator AND. In English Congenital Hypothyroidism, Pediatric, Drug Therapy, as well as the term L-Thyroxine, was introduced, using the Boolean operator AND. ${ }^{11-13}$

\section{Study selection process}

After applying the primary screening, based on the date of publication of the article, main topic, and type of study. We proceeded to the evaluation of the quality of the works according to the suggestions of authors such as Pazzini et al. ${ }^{7}$ who proposed a design of selection criteria for the evaluation of the quality of the works, this was taken up and modified to analyze exclusively clinical trials. These criteria can be seen below:

i. Study design: randomized clinical trials (RCT), controlled 
clinical trials (CCT): 3 points, clinical trials (TC): 1 point.

ii. Appropriate sample size: 1 point.

iii. An appropriate description of the selection: 1 point.

iv. Valid measurement methods: 1 point.

v. Use of method error analysis: 1 point.

vi. Blinding in the measurements: 1 point.

vii. Appropriate statistical methods: 1 point.

viii. Confusion factors included in the analysis: 1 point.
The methodological quality of the studies evaluated was divided into three categories: From 0 to 5 points were considered of low methodological quality; those works evaluated from 6 to 8 points were considered of medium quality, and finally, those evaluated from 9 to 10 points as high quality. ${ }^{14-16}$

\section{Results}

The strategy used in the bibliographic search produced a total of 29 potential references. After the selection and application of the eligibility criteria in the evaluation of the quality of the recovered works, only 3 publications qualified for the final analysis (Table 1). ${ }^{17-19}$

Table I Papers

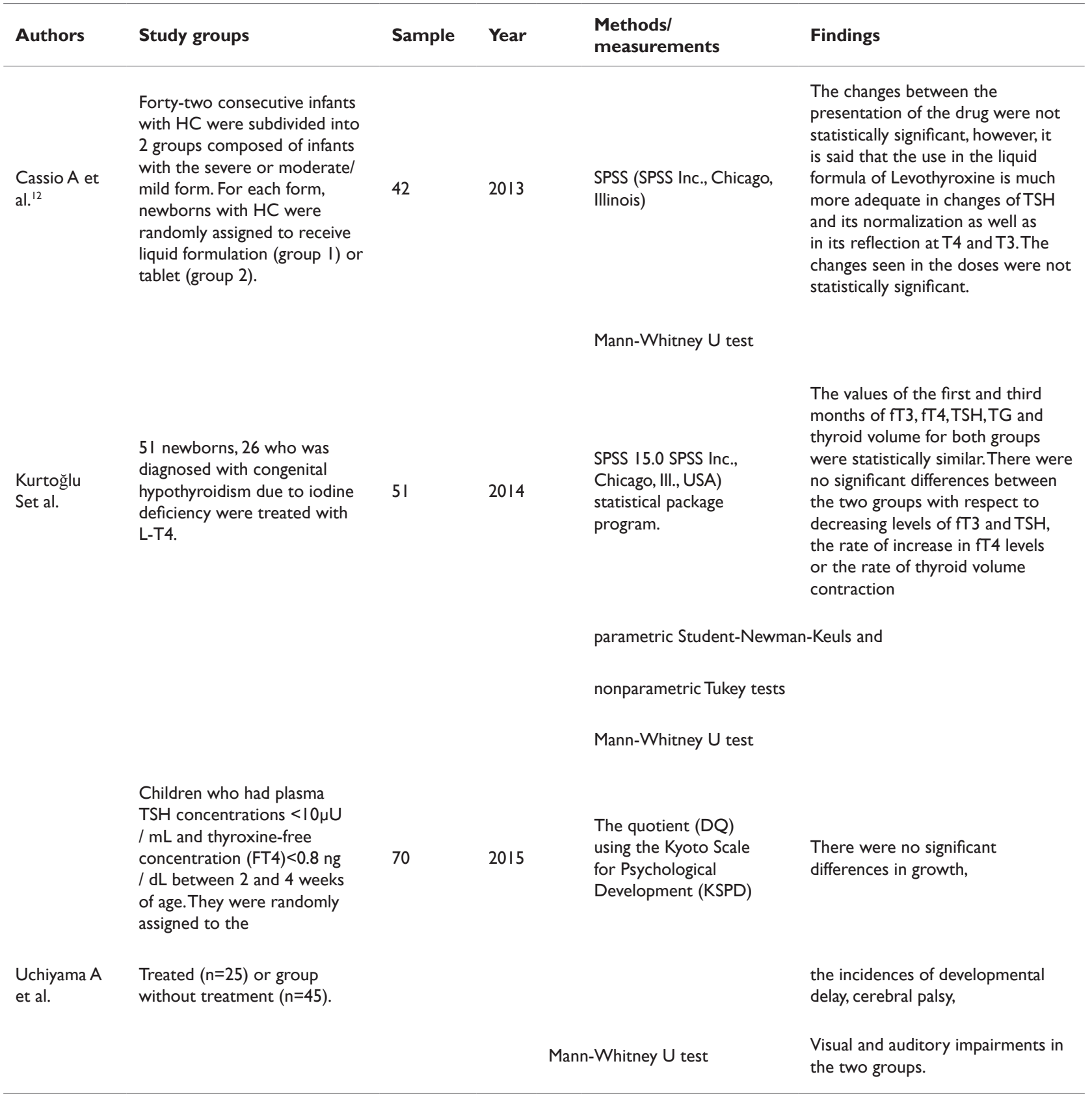




\section{Quality of the works}

The quality of the research and the methodology applied to the development of the reviewed clinical trials gave us as a result: 1 articles of low quality, 2 articles of medium quality and no article of high quality was obtained (Table 2) 3 articles were considered; 2 of medium quality and 1 of low quality, for purposes of the purpose of the work, the publication dates of the works ranged between 2012 and 2017, focused on patients with HC treated with hormone replacement therapy. All the articles found clinically significant medical evidence that showed an improvement in the somatometric and cognitive status of the patients who were treated with levothyroxine in hormone replacement therapies, for periods longer than 2 years of treatment, causing a positive impact on the improvement of the symptoms of $p$, for periods longer than 2 years of treatment, causing a positive impact on the improvement of patient symptoms. The groups/individual of study, the size of the population sample, year of publication of the work, methods, and measurements applied in the realization of the work and the relevant findings are described. ${ }^{20-23}$

Table 2 Evaluation of quality in the recovered works

\begin{tabular}{|c|c|c|c|c|c|c|c|}
\hline Authors & $\begin{array}{l}\text { study } \\
\text { design }\end{array}$ & Sample & $\begin{array}{l}\text { Selection } \\
\text { description }\end{array}$ & $\begin{array}{l}\text { Validated } \\
\text { measurements } \\
\text { and methods }\end{array}$ & $\begin{array}{l}\text { Method error } \\
\text { analysis }\end{array}$ & Blind level & $\begin{array}{l}\text { Confounding } \\
\text { factors } \\
\text { considered }\end{array}$ \\
\hline Cassio $A$ et al. ${ }^{12}$ & CCT & Suitable & Suitable & yes & yes & yes & not specified \\
\hline Kurtoğlu Set al. & $\mathrm{CCT}$ & Inadequate & Inadequate & yes & & & not specified \\
\hline Uchiyama $A$ et al. & CCT & Inadequate & Inadequate & yes & not specified & $\begin{array}{l}\text { not } \\
\text { specified }\end{array}$ & not specified \\
\hline
\end{tabular}

\section{Discussion}

The presentations found in the studies were limited to liquid formula and tablets. ${ }^{7}$ Replacement therapy leads to an improvement in cognitive function. ${ }^{8}$ In the review of the literature, an important reduction in intellectual deterioration and growth was found. ${ }^{9}$ DOSE. Ahmad $^{10}$ recorded important measures to consider regarding TSH values and the amount of recommended dose to administer, with the initial recommendation standing out from the total revision of $10-15 \mu \mathrm{g} / \mathrm{kg} /$ day. The treatment with liquid formula compared to the usual treatments of tablets reflects a difference ${ }^{24}$ not statistically significant, which nevertheless showed some increased improvement in the application of liquid solutions with the normalization of TSH and T4 levels. Regarding the recommended doses, it was possible to determine the levels of FT4, being less than $5 \mathrm{pmol} / \mathrm{L}$. In the clinical practice guide the initial dose of $10-15 \mu \mathrm{g} / \mathrm{kg} /$ day and adjustments according to the patient's age administration of said medication in a minimum interval of two hours before the food, as it decreases its absorption. Follow-up by measuring the serum values of this every six to eight weeks to decide if the dose should be readjusted. The use of these higher doses in cases of severe $\mathrm{HC}$ and, if possible, the availability of liquid levothyroxine solutions, demonstrated data that, although they were not statistically significant, that there was a better improvement of patients in the areas of growth and development cognitive..$^{25-29}$

\section{Conclusion}

The articles demonstrated medical evidence of improvement in somatometric and cognitive status in patients, causing an impact on symptom relief. The untreated $\mathrm{CH}$ causes alterations of the growth and mental retardation, its severity produces deep and irreversible neurological alterations, the reason why the opportune treatment after the birth is indispensable.

\section{Acknowledgements}

None.

\section{Conflict of interest}

The author declares there is no conflict of interest.

\section{References}

1. American Academy of Pediatrics, Rose SR, American Thyroid Association, et al. Update of newborn screening and therapy for congenital hypothyroidism. Pediatrics. 2006;117(6):2290-2303.

2. Gruters A, Krude H. Update on the management of congenital hypothyroidism. Horm Res. 2007;68(Supp 1):107-111.

3. Leggio GM, Incognito T, Privitera G, et al. Comparative bioavailability of different formulations of levothyroxine and liothyronine in healthy volunteers. J Endocrinol Invest. 2006;29(11):RC35-RC38.

4. Blakesley VA. Current methodology to assess the bioequivalence of levothyroxine sodium products is inadequate. AAPS J. 2005;7(1):E42E46.

5. American Thyroid Association, The Endocrine Society, American Association of Clinical Endocrinologists. Joint statement on the U.S. Food and Drug Administration's decision regarding bioequivalence of levothyroxine sodium. Thyroid. 2004;14(7):486.

6. Grussendorf $M$, Vaupel $R$, Wegscheider $K$. Bioequivalence of L-thyroxine tablets and a liquid L-thyroxine solution in the treatment of hypothyroid patients. Med Klin. 2004;99:639-644.

7. La Franchi SH, Austin J. How should we be treating children with congenital hypothyroidism? J Pediatr Endocrinol Metab. 2007;20:559578.

8. Touati G, Leger J, Toublanc JE, et al. A thyroxine dosage of $8 \mathrm{mg} / \mathrm{kg}$ per day is appropriate for the initial treatment of the majority of infants with congenital hypothyroidism. Eur J Pediatr. 1997;156(2):94-98.

9. Von Heppe JH, Krude H, L'Allemand D. The use of L-T4 as liquid solution improves the practicability and individualized dosage in newborns and infants with congenital hypothyroidism. J Pediatr Endocrinol Metab. 2004;17(7):967-974.

10. Wasniewska M, De Luca F, Cassio A, et al. In congenital hypothyroidism 
bone maturation at birth may be a predictive factor of psychomotor development during the first year of life irrespective of other variables related to treatment. Eur J Endocrinol. 2003;149(1):1-6.

11. Bisacchi N, Bal MO, Nardi L. Psychological and behavioural aspects in children and adolescents with congenital hypothyroidism diagnosed by neonatal screening: comparison between parents' and children's perceptions. Eur J Endocrinol. 2011;164:269-276.

12. Cassio A, Cacciari E, Cicognani A, et al. Treatment for congenital hypothyroidism: thyroxine alone or thyroxine plus triiodothyronine? Pediatrics. 2003;111(5 Pt 1):1055-1060.

13. Griffiths R. GMDS-R Griffiths Mental Development Scales-Revised Edition revised by Huntley M. 1996.

14. Ng SM, Anand D, Weindling AM. High versus low dose of initial thyroid hormone replacement for congenital hypothyroidism. Cochrane Database Syst Rev. 2009;2: CD006972.

15. Hrytsiuk I, Gilbert R, Logan S, et al. Starting dose levothyroxine for the treatment of congenital hypothyroidism a systemic review. Arch Pediatr Adolesc Med. 2002;156(5):485-491.

16. Rastogi MV, LaFranchi SH. Congenital hypothyroidism. Orphanet JRare Dis. 2010;5:1-22.

17. Jones JH, Geller G, Paterson F. Effect of high versus low initial doses of L-thyroxine for congenital hypothyroidism on thyroid function and somatic growth. Arch Dis Child. 2008;93(11):940-944.

18. Rovet JF. Long-term neuropsychological of early-treated congenita hypothyroidism: effect in adolescence. Acta Paediatr Suppl. 1999;88(432):88-95.

19. Alvarez M, Iglesias Fernandez C, Rodriguez Sanchez A. Episodes of overtreatment during the first six months in children with congenital hypothyroidism and their relationships with sustained attention and inhibitory control at school age. Horm Res Paediatr. 2010;74:114-120.
20. Dubuis JM, Glorieux J, Richer F, et al. Outcome of severe congenital hypothyroidism: closing the developmental gap with early high dose levothyroxine treatment. J Clin Endocrinol Metab. 1996;81(1):222-227.

21. Salerno M, Oliviero U, Lettiero T, et al. Long-term cardiovascular effects of levothyroxine therapy in young adults with congenital hypothyroidism. J Clin Endocrinol Metab. 2008;93(7):2486-2491.

22. Flores-Huerta S, Hernandez-MontesH, Argote RM, et al. Effects of ethanol consumption during pregnancy and lactation on the outcome and postnatal growth of the offspring. Ann Nutr Metab. 1992;36(3):121-128.

23. Little RE, Northstone K, Golding J, e al. Alcohol, breastfeeding, and development at 18 months. Pediatrics. 2002;109.E72-E72.

24. O'Leary CM, Nassar N, Zubrick SR. Evidence of a complex association between dose, pattern and timing of prenatal alcohol exposure and child behaviour problems. Addiction. 2010;105:74-86.

25. Dimitropoulos A, Molinari L, Etter K, et al. Children with congenital hypothyroidism: long-term intellectual outcome after early high-dose treatment. Pediatr Res. 2009;65(2):242-248.

26. Radwin LS, Michelson JP, Berman AB, et al. End results in treatment of congenital hypothyroidism; follow-up study of physical, mental and behavioral development. Am J Dis Child. 1949;78(6):821-843.

27. Fisher DA, Dussault JH, Foley TP, et al. Screening for congenital hypothyroidism: results of screening one million North American infants. J Pediatr.1979;94(5):700-705.

28. Illig R, Gitzelmann R. Screening for congenital hypothyroidism. $J$ Pediatr. 1977;91(2):348-349.

29. Clerc J, Monpeyssen H, Chevalier A, et al. Scintigraphic imaging of paediatric thyroid dysfunction. Horm Res. 2008;70(1):1-13. 